DOI 10.37882/2223-2982.2020.12-2.23

\title{
СОВЕТСКОЕ ТРАКТОРОСТРОЕНИЕ КАК ПРОИЗВОДСТВЕННАЯ БАЗА РАЗВИТИЯ ТАНКОВОЙ ПРОМЫШЛЕННОСТИ: ПЛАНЫ И РЕАЛЬНОСТЬ (1920-1945 ГГ.)
}

\section{SOVIET TRACTOR INDUSTRY AS A PRODUCTION BASE FOR THE DEVELOPMENT OF TANK INDUSTRY: PLANS AND REALITY (1920-1945)}

N. Melnikov

Summary: The Soviet civil and military leadership at the start of industrialization jump of the first five-year plans considered tractor industry as the main production base for the development of tank industry. Many researchers evaluates the work of Albert Kahn, whose firm designed all three Soviet tractor plants (Stalingrad, Kharkov, and (helyabinsk), as one of the main success factors in creating the Soviet tank industry. However, during the 1930s, all attempts to establish mass production of armored vehicles at tractor factories regularly failed, and the outbreak of the Great Patriotic war actually led to the temporary loss of Soviet tractor industry. Consequently, tractor plants could not become the real basis of the Soviet tank industry.

Keywords: Stalinism, Albert Kahn, tractor plants, tank industry, industrialization, war.

\author{
Мельников Никита Николаевич \\ К.и.н., с.н.с., Институт истории и археологии УрО РАН \\ (Екатеринбург) \\ meln2011kit@gmail.com
}

Аннотация: Советское гражданское и военное руководство на старте индустриализационного скачка первых пятилеток рассматривало тракторную промышленность как основную производственную базу для развития танкостроения. Многие исследователи расценивают деятельность Альберта Кана, фирма которого спроектировала все три советские тракторные заводы (Сталинградский, Харьковский и Челябинский), как один из основных факторов успеха в создании советской танковой промышленности. Но в течение 1930-х гг. попытки наладить массовый выпуск бронетехники на тракторных заводах регулярно терпели неудачу, а начавшаяся Великая Отечественная война фактически привела к временной утрате советского тракторостроения. Следовательно, тракторные заводы так и не смогли стать настоящей основой советского танкопрома.

Ключевые слова: сталинизм, Альберт Кан, тракторные заводы, танковая промышленность, индустриализация, война.

Танкостроение стало для советской индустрии той самой отраслью, которая была рождена в период первых пятилеток и уже к началу 1940-х г. оказалась способна выпускать тысячи танков ежегодно. Всего в июне 1941 г. на вооружении Красной Армии состояло более 22 тыс. отечественных танков различных модификаций [1, с. 220]. Вполне естественно, что такой значимый успех привлекал и привлекает внимание исследователей, пытающихся объяснить этот феномен.

В современной литературе распространена точка зрения, согласно которой начало танкостроения было заложено одним из крупнейших промышленных архитекторов XX века Альбертом Каном, основателем одноименной фирмы «Albert Kahn, Inc.» (США), спроектировавшей между 1929 и 1932 гг. более 500 промышленных объектов в СССР и (что важно для нашего исследования) все тракторные заводы: Сталинградский, Харьковский и Челябинский [2, с. 342]. Именно эти три предприятия, по мнению некоторых исследователей, во-первых, изначально планировались как заводы двойного назначения (тракторно-танковые), а во-вторых, стали основой для советского танкостроения и обеспечили СССР бронетехникой $[2$, с. 340-343; 3, с. 138-139; 4, 101-105; 5, с. 57-59; и др.]. 
Данная точка зрения, видимо, имеет свои корни в мнении американского журналиста Г.Р. Никербокера, побывавшего в 1931 г. на строительстве Челябинского тракторного завода: «По твердому убеждению большевистских пессимистов, строящаяся сейчас тракторная фабрика в Челябинске может почти моментально быть переориентирована на военные цели для отражения ожидаемого нападения капиталистического мира. Планируемый выпуск 50000 штук десятитонных 60-сильных гусеничных тракторов в год, очень сильно напоминающих танки, означает, что речь идет о производстве одного из типов танков» [6, с. 66-68 (цит. по: 4, с. 105)]. Впоследствии эта позиция распространилась в зарубежной литературе и уже оттуда попала в отечественную историографию.

В действительности ситуация развивалась в значительной степени иначе. Советское танкостроение зародилось и развивалось отнюдь не на предприятиях, спроектированных Каном. Но в одном сторонники версии становления советского танкостроения на основе тракторной промышленности правы: руководство страны долгое время пыталось развивать эти две отрасли вместе, а сама идея двойных технологий стала популярна среди руководителей Красной Армии и государства.

Если подходить к вопросу появления первых советских танков формально, то родиной советского танкового производства можно считать нижегородский Сормовский завод, который до революции выпускал пароходы и паровозы. Именно здесь на основе трофейного «Renault FT-17» в течение 1920-1921 гг. было собрано и выпущено 15 танков, получивших название «Русский Рено» [7, с. 3449]. Это была небольшая партия машин, и дальнейшего развития этот опыт не получил.

В середине 1920-х гг. начались работы по созданию Сталинградского тракторного завода (СТ3). Еще до подключения к его проектированию А. Кана (которое случится в 1929 г.), весной 1928 г. советское руководство в рамках реализации задач первой пятилетки решило начать подготовку танкового производства на будущем тракторном заводе. Первоначально ожидалось, что выпуск первых советских танков Т-18 (MC-1) начнется во второй половине 1930/1931 хозяйственного года. Впоследствии СТЗ должен был стать основным центром танкового производства СССР и выпускать более половины всех советских танков. А пока СТЗ не вступил в строй, было решено временно развернуть выпуск Т-18 на пермском Мотовилихинском заводе'. Также изготовление танков должны были наладить Харьковский паровозостроительный завод (ХПЗ) и ленинградский завод
«Большевик» [8, с. 161-162].

Пионером советского серийного танкового производства стал завод «Большевик» (бывший Обуховский завод), когда в 1927-1928 гг. освоил выпуск Т-18. Справедливости ради нужно сказать, что именно на «Большевике» было создано одно из первых в СССР тракторных производств, в рамках которого как раз и возник участок по изготовлению танков. Но в 1930-1932 гг. произошла полная переориентация танкостроения на новые образцы бронетехники, созданных на базе импортных моделей и отечественных разработок. После этого советские системы тракторной и танковой промышленностей стали постепенно расходиться друг от друга. Это процесс продолжался до конца 1930-х гг. до тех пор, пока не произошло очередное перевооружение.

В 1932 г. танковое производство «Большевика» было выделено в самостоятельный завод № 174 им. имени К.Е. Ворошилова, где вплоть до начала 1940-х гг. производились легкие общевойсковые танки Т-26. В 1932 г. ленинградский завод «Красный Путиловец» (до революции - Путиловский завод, а с 1934 г. - Кировский завод) начал производство трехбашенного танка качественного усиления резерва Главного командования Т-28. Разведывательные плавающие танки Т-37 с 1932 г. выпускал московский завод № 2 Всесоюзного автотракторного объединения (впоследствии завод № 37 им. Орджоникидзе), возникший на основе авторемонтных мастерских 2-й автомобильной роты Техуправления Императорской армии. Примерно в это же время ХПЗ освоил крупносерийное производство оперативного колёсно-гусеничного танка серии БТ и мелкосерийный выпуск пятибашенного 50-тонного танка особого назначения Т-35.

Следовательно, серийное советское танкостроение появилось и развивалось на основе производственных мощностей заводов, построенных ещё в дореволюционной России. Основная роль здесь де-факто была отведена крупнейшим заводам паровозостроения и судостроения еще дореволюционной России - ХПЗ и бывшему Путиловскому заводу. Советская тракторная промышленность только начинала зарождаться в самом начале 1930-х гг. (полукустарный выпуск тракторов советской промышленностью 1920-х гг. нельзя считать полноценным массовым производством). Все три «кановских» завода (Сталинградский, Харьковский и Челябинский) в тот момент находились в стадии активного строительства или наладки производственного цикла. Именно поэтому на них еще трудно было рассчитывать в деле развития танкового производства СССР.

Решение о начале производства танков на Мотовилихе было принято с достаточно странным обоснованием: «в качестве временной меры возможно было бы условно согласиться на развертывание производства Т-18 на Пермском заводе» [8, с. 161-162]. Это показывает изначальные сомнения в успешности этого проекта. И действительно, попытки наладить выпуск танков в Перми продолжались около трех лет, и в мае 1931 г. эта программа была свернута с формулировкой: «Больше танковых заказов на Мотовилиху не давать». [8, с. 545-546.]. 
Тем не менее, сталинское руководство действительно пыталось использовать потенциал развивающейся тракторной промышленности для нужд танкопрома. В конце первой пятилетки был разработана программа ускоренного развития танкостроения, где к концу второй пятилетки ожидалось, что первенство в производстве танков перейдет к тракторным заводам (СТ3 и ЧТЗ) [9, с. 189]. Но уже в начале следующей пятилетки планы начали корректироваться. Развитие советского танкостроения подразумевалось тремя производственными центрами:

Северная база (Ленинград). Завод им. Ворошилова (№ 174) - сборка танков Т-26, «Красный путиловец» (Кировский завод) - сборка танков Т-28, «Красный Октябрь» - изготовление узлов и агрегатов для танков и тракторов, Ижорский завод - выпуск брони и бронекорпусов.

Центральная база (Москва, Горький). Московский завод № 37 и Горьковский автозавод - сборка танков Т-37, Кулебакский, Подольский заводы, Выксунский металлургический завод и Выксунский завод дробильно-размолочных машин - броневое и бронекорпусное производство.

Южная база (Харьков, Сталинград). Харьковский паровозостроительный завод - танки Т-35 и Т-26, Сталинградский тракторный - Т-26, Харьковский тракторный завод ${ }^{2}$, Мариупольский металлургический - танковая броня [10, с. 195].

Но и в ходе второй пятилетки не удалось полностью реализовать развитие новой производственной основы танкостроения. В заявленном составе действовала только Северная база. В Центральной базе относительно успешно работали (выпускали продукцию в рамках танкопрома) только московский завод № 37 и Подольский крекинг-завод. В южном центре в реальном изготовлении танков были задействованы только ХПЗ и Мариупольские завод. Обнаружить документов, подтверждающих участие ХT3 в танкостроительной программе в этот период, нам пока не удалось. Но Сталинградский тракторный завод действительно пытался организовать это производство.

Создание танкосборочного участка на СТ3 шло с большим трудом с самого начала, но далее выпуска ограниченного количества готовой бронетехники заводу продвинуться не удалось: около 5 машин было изготовлено в 1933 г., 23 танка в 1934 г. и 115 в 1935 году [11, с. 113; 12, с. 61]. По данным исследователя М. Коломийца, в дальнейшем завод выпустил еще какое-то количество Т-26, но уже во второй половине 1930-х гг. их производство практически остановилось. Автор считает, что сталинградские машины «имели более низкую надежность», чем ленинградские [12, с. 61]. Интересно, что в статистическом сборнике «Справочник. Основные средства производства и технико-экономические показатели работы Наркомтанкопрома. 1942-1945 гг.» присутствуют данные по выпуску всех танков на всех заводах страны с 1931 по 1945 годы. Но в этом сборнике нет информации о танках СТ3 1930-х годов. Первая сталинградская бронетехника (Т-34) появляется в нем только в 1941 году [13, л. 158-164].

В конце второй пятилетки советское руководство продолжало рассматривать тракторостроение как потенциальную основу танковой промышленности и вновь рассчитывало организовать массовый выпуск танков на СТ3 и ЧТЗ. Но не ранее третьей пятилетки [10, с. 657].

Действительно, в 1940 г. началось реальное расширение промышленной базы советского танкостроения за счёт тракторной промышленности. В конце 1939 г. советское правительство приняло на вооружение новые образцы бронетехники: легкий плавающий танк Т-40 (завод № 37), средний танк Т-34 (ХПЗ), тяжёлый танк КВ (Кировский завод) и дизельный танковый двигатель В-2 (Харьковский дизель-моторный завод № 75) ${ }^{3}$.

В самом конце 1939 г. Вышел приказ наркома среднего машиностроения И.А. Лихачёва, в том числе конкретизирующий план текущих заказов по танкостроению. Помимо основного завода-изготовителя (ХПЗ), приказ санкционировал изготовление Т-34 на СТЗ. Сталинградский завод должен был немедленно прекратить подготовку выпуска Т-26 (это еще одно подтверждение того, что СТ3 так и не смог справиться с программой Т-26), в течение 1940 г. выпустить 20 машин и подготовить свои мощности на 2 тыс. Т-34 в год [14, л. 221-226]. Но аппетиты советского руководства росли, и уже в июне 1940 г. вышло постановление СНК и ЦК ВКП(б) о плане производства нового танка до конца года, согласно которому ХПЗ должен был изготовить 500 танков, а СТ3 - 100 [15, c. 23].

Однако реальность не соответствовала планам. В итоге Сталинградский завод в 1940 г. так и не смог освоить производство Т 34. На 1 января 1941 г. на заводе было собрано 23 танка, из них только 6 прошли испытания, но ни один танк не был принят военпредами [16, л. 72-76]. Именно поэтому в «Справочнике» Наркомата танковой промышленности первые сталинградские танки датированы только 1941 годом - после завершения сборки боевые машины должны были быть приняты военной приёмкой (военпредом), и только тогда изготовленный танк засчитывался как действительно выпущенный.

\footnotetext{
2 Источник не дает его назначения. Видимо, по аналогии с «Красным Октябрем», ХТ3 должен был выпускать запчасти к танкам.

3 К началу 1941 г. на заводе № 174 был разработан и принят на вооружение новый лёгкий танк поддержки пехоты Т-50.
} 
В рамках развития военного производства в 1940 г. было санкционировано дальнейшее расширение производственной базы танкостроения за счет тракторной промышленности. Тяжелые танки серии КВ решено было изготавливать в Челябинске. Приказом по Наркомату среднего машиностроения от 20 июня 1940 г. на Челябинском тракторном заводе предписывалось организовать сборочное производство тяжелых танков серии «КВ». До конца года необходимо было выпустить опытную партию танков в количестве 5 шт., а в следующем году перейти на серийное производство - 300 танков [17, л. 59-85; 18, л. 151].

Свой первый танк ЧТЗ выпустил так же, как и СТЗ, только в январе 1941 г., что фактически означало срыв планов по подготовке сборочного участка танкового производства в течение второй половины 1940 года $[19$, c. 13].

Данный этап развития новых восточных производственных баз танкостроения наглядно свидетельствует, что обоим тракторных предприятиям было поручено задание, справиться с которыми самостоятельно и в установленные сроки они были не в состоянии. И СТЗ, и ЧТЗ сорвали сроки подготовки танкосборочного участка. Необходимо было создать условия для существенного увеличения объёма производственных ресурсов обоих центров.

26 ноября 1940 г. нарком средмаша В.А. Малышев направил в ЦК ВКП(б) и СНК докладную записку с предложением организовать на СТЗ вторую базу по производству дизеля В-2 [20, с. 661]. После чего СТ3 был вынужден начинать организацию выпуска В-2 параллельно с уже существующей программой Т-34 и тракторостроением. Такое распыление ресурсов не могло завершиться успехом. В марте 1941 г. нарком Госконтроля Л.3. Мехлис констатировал, что СТ3 «как база моторостроения для Т-34 совершенно не готов» [20, с. 791].

К середине 1941 г. ни одна из поставленных задач решена не была. Как и на предыдущих этапах, предприятия не могли справиться со всем объемом правительственных заданий в установленные сроки.

С началом Великой Отечественной войны сталинское руководство пошло на дальнейшее расширение танкостроительной программы. Только с этого времени начинается реальное, но недолгое вхождение Харьковского тракторного завода в систему танковой промышленности. На ХТЗ и ГАЗе стартовала подготовка производства легких танков Т-604, которая впоследствии закончилась относительно успешно. Начал готовиться к выпуску Т-34 горьковский завод № 112 («Красное Сормово»). В начале июля 1941 г. СТ3 обязывался к сентябрю в срочном по- рядке закончить подготовку дизельного производства и до конца года изготовить 500 дизельных двигателей. Для обеспечения нового правительственного задания в начале июля 1941 г. на площадку СТ3 перемещалось авиадизельное производство ХТ3 [21, л. 313-314]. Так, вместе с новым заданием СТ3 получил и новые ресурсы, которые в значительной степени облегчали задачу организации моторного производства.

На Урале было принято решение организовать вторую комплексную базу по изготовлению танков КВ. ЧТЗ не только сохранил сборочное производство, но должен был резко расширить его. Производство танковых дизелей В-2 должен был организовать Уральский турбинный завод (Свердловск). Для обеспечения этой программы в Свердловск был переброшены авиадизельный цех Кировского завода $[22$, л. 122; 23, л. 2; 24, л. 35, 42]. Таким образом, будущая база дизельного производства в Сталинграде и Свердловске стала формироваться на основе перемещенного авиационного дизелестроения.

Однако уже осенью 1941 г. география танковой промышленности СССР была вновь изменена. Стремительное продвижение противника на восток заставило советское руководство санкционировать эвакуацию всех западных танковых заводов. Танковое производство Кировского завода и дизельный завод № 75 уехали в Челябинск на ЧТЗ (объединенное предприятие стало называться «Кировский завод в г. Челябинск»). Перестал существовать (в рамках танкостроения) ХТЗ. Он был эвакуирован в Сталинград на завод № 264 (выпуск легких танков Т-60 и бронекорпусов Т-34 для СТ3). Но уже летом 1942 г. перестал действовать СТ3: пришлось эвакуировать весь сталинградский промышленный центр из-за наступления противника на Волгу и Кавказ. Оборудование и кадры нижневолжских заводов Наркомата танкопрома были распределены между другими танкостроительными центрами.

В момент создания танкового производства в СССР на рубеже 1920-1930-х гг. советское военное и гражданское руководство рассматривало тракторную промышленность как основную базу для развития танкостроения. Но реально тракторные заводы начали участвовать в этом проекте буквально накануне Великой Отечественной войны, и уже в течение первого года войны формально ни одного предприятия тракторостроения в СССР не осталось. Харьковский и Сталинградский заводы пришлось эвакуировать. И хотя СТЗ уже в конце 1943 г. приступил к ремонту поврежденных танков и двигателей, а в следующем году начал даже участвовать в изготовлении нового танка Т-44, его вклад в танкостроение все же оставался незначительным. Столь сильны были разрушения, полученные в результате обороны Сталинграда.

4 Модернизированный вариант Т-40. 
Оставался ЧТЗ, который теперь назывался Кировским заводом и наследовал производственную архитектуру, заложенную проектом А. Кана. Но, во-первых, его новое положение настолько изменилось, что потребовалась серьезная перестройка всего комплекса цехов и производственных процессов. Конструкции тракторных заводов проектировались под конвейерную технологию, тогда как кировское танкостроение было рассчитано исключительно на «стационарную сборку». В ходе реорганизации производства в Челябинске многое удалось изменить, но фактически конвейерный метод был применен на челябинском Кировском заводе только в конце 1943 г., когда было запущено производство новых тяжелых танков серии ИС. Во-вторых, челябинский завод, хоть и самый крупный в системе танковой промышленности, был все же одним из десятков других пред-

\section{приятий отрасли.}

Следовательно, тезис о решающем вкладе фирмы «Albert Kahn, Inc.» именно в развитие танкового производства СССР как минимум страдает серьезными преувеличениями. Как показывают документы, все предвоенные и военные годы роль тракторных заводов в деле производства танков оставалась крайне незначительной. И в то же время, деятельность А. Кана имела серьезное влияние не только на танкопром, но и на всю военную промышленность СССР. Фирма «Albert Kahn, Inc.» участвовала в проектирование многих металлургических и машиностроительных заводов, которые были задействованы в танкостроении. В том числе Горьковский автомобильный и Магнитогорский металлургический. В этом смысле, роль Альберта Кана, безусловно, была значительна.

\section{ЛИТЕРАТУРА}

1. Россия и СССР в войнах XX века. Потери вооруженных сил: Статистической исследование / Под общ. ред. Г.Ф. Кривошеева. М.: 0ЛМА-ПРЕСС, 2001. 607 с.

2. Хмельницкий. Д. Танки за хлеб. Американские корни советской военной промышленности // Правда Виктора Суворова-2. Восстанавливая историю Второй мировой / Сост. Д. Хмельницкий. М.: Яуза-Пресс, 2007. С. 330-348.

3. Меерович М.Г., Хмельницкий Д. Роль иностранных архитекторов в становлении советской индустриализации // Пространственная экономика. 2005. № 4. С. 131-149

4. Хмельницкий Д.С., Меерович М.Г. Американские и немецкие архитекторы в борьбе за советскую индустриализацию // Вестник Евразии. 2006. № 1. С. 92-123

5. Sonia Melnikova-Raich. The Soviet Problem with Two "Unknowns": How an American Architect and a Soviet Negotiator Jump-Started the Industrialization of Russia, Part I: Albert Kahn, IA: The Journal of the Society for Industrial Archeology 36, no. 2 (2010): 57-80.

6. Knickerbocker H.R. Der Rote Handel droht. Berlin, 1931. $202 \mathrm{~s}$.

7. Свирин М.Н. Броня крепка. История советского танка. 1919-1937. М.: Яуза, Эксмо, 2005. 348 С.

8. Становление оборонно-промышленного комплекса СССР (1927-1937). Т. З. Часть 1 (1927-1932): Сборник документов / Под ред. А.А. Кольтюкова. Отв. сост. Т.В. Сорокина. М.: ТЕРРА - Книжный клуб, 2008. 912 с.

9. Самуэльсон Л. Красный колосс. Становление военно-промышленного комплекса СССР. 1921-1941. М.: АИРО-ХХ, 2001. 296 с.

10. Становление оборонно-промышленного комплекса СССР (1927-1937). Т. 3. Часть 2 (1933-1937): Сборник документов / Под ред. А.А. Кольтюкова. Отв. сост. Т.В. Сорокина. М.: 000 «Издательство ТЕРРА», 2011. 944 с.

11. Бугров К.Д., Запарий В.В. Танкостроение в контексте военно-хозяйственной стратегии ССсР 1930-х гг. // Вестник Томского государственного университета. 2019. № 448. С. 108-118

12. Коломиец М. В. Т-26. Тяжелая судьба легкого танка. М.: Эксмо, 2007. 154 с.

13. Российский государственный архив экономики (РГАЭ). Ф. 8752. 0п. 4. Д. 728.

14. РГАЭ. Ф. 8115. ОП. 8. Д. 21.

15. Желтов И., Павлов М., Павлов И. Неизвестный Т-34. М.: Экспринт, 2001. 184 с.

16. РГАЭ. Ф. 8115. ОП. 8. Д. 79.

17. Объединённый государственный архив Челябинской области (ОГАЧО). Ф. Р-792. Оп. 1. Д. 57.

18. ОГАЧО. Ф. П-288. ОП. 42. Д. 14. Л. 151.

19. Валеев Р.Р. Рекорды Челябинского тракторного завода // Военно-исторический журнал. 2003. № 3. С. 13-15.

20. Оборонно-промышленный комплекс СССР накануне Великой Отечественной войны (1938 - июнь 1941 г.).: Т. 4. Сборник документов / Под редакцией А.К. Соколова. Сост.: Т.В. Сорокина и др. М.: Книжный Клуб Книговек, 2015. 1120 с.

21. РГАЭ. Ф. 8115. ОП. 8. Д.82.

22. Государственный архив Свердловской области (ГАСО). Ф. Р-262. Оп. 1. Д. 17.

23. ГАСО. Ф. Р-262. ОП. 1. Д. 71. Л. 2;

24. ГАСО. Ф.Р-1930. ОП. З. Д. 11. Л. $35,42$.

(с) Мельников Никита Николаевич (meln2011 kit@gmail.com). 